\title{
Determination of Ambient Noise Levels and Perception of Residents in Halls at the University of Cape Coast, Ghana
}

\author{
Paul K. Essandoh (Corresponding author) \\ Department of Environmental Science, School of Biological Sciences \\ University of Cape Coast, Ghana \\ Tel: 233-424-415-8690Ｅ-mail: Parosepa@yahoo.com
}

Frederick A. Armah

Department of Environmental Science, School of Biological Sciences

University of Cape Coast, Ghana

Tel: 233-424-948-3014Ｅ-mail: farmah@ucc.edu.gh

Ernest K.A. Afrifa

Department of Environmental Science, University of Cape Coast, Ghana

Tel: 233-241-798-570 E-mail: e_afrifa@yahoo.co.uk

Alexander N. M. Pappoe

Department of Environmental Science, School of Biological Sciences

University of Cape Coast, Ghana

Tel: 233-424-487-9965Ｅ-mail: anmpappoe@yahoo.com

Received: August 26, $2011 \quad$ Accepted: October 19, $2011 \quad$ Published: December 1, 2011

doi:10.5539/enrr.v1n1p181

URL: http://dx.doi.org/10.5539/enrr.v1n1p181

\begin{abstract}
Environmental noise pollution generated from industrial and transport activities in Ghana have received considerable attention from regulators and policy makers. However, rising noise levels in residential settings have received little attention. This study measured ambient noise levels in four halls of residence in the University of Cape Coast, Ghana to ascertain compliance with permissible limits and determine the peak period of the noise generated. Questionnaires were also used to evaluate the possible non-auditory noise effects. The results indicate that noise generated within the functional units ranged from $30 \mathrm{~dB}$ to $70 \mathrm{~dB}$. The same- sex halls (Adeyhe and Casford) were within the day and night permissible noise limits (55dB and 50dB respectively) set by the Ghana Environmental Protection Agency. However, the Oguaa and Valco Halls (mixed halls) were non-compliant. Adehye Hall recorded the lowest for both day (49dB) and night (45dB). Valco Hall recorded the highest noise level for both day and night: $66 \mathrm{~dB}$ and $60 \mathrm{~dB}$ respectively. Oguaa Hall, the largest on campus, had $60 \mathrm{~dB}$ and $55 \mathrm{~dB}$ for day and night. Casford Hall, the only male hall recorded $54 \mathrm{~dB}$ and $48 \mathrm{~dB}$ respectively for day and night readings. This was unexpected as most students considered Casford to be noisy. Most of the participants complained that the noise affects their studies and sleep in the halls. Surprisingly, majority of the students $(73 \%)$ were not of the view that reducing noise levels could potentially make the halls more habitable. Association between halls of residence and annoyance levels was investigated. The P-Value (0.180) was greater than the alpha value (0.05). Consequently we failed to reject the null hypothesis and concluded that, there is no association between the halls of residence and level of irritation of students in the halls.
\end{abstract}

Keywords: Non-auditory noise effects, Irritation, Students, Residential setting, University 


\section{Introduction}

Noise pollution has become problematic yet an unnoticed form of pollution in most developing countries including Ghana. Due to industrialization and urbanization, noise pollution has gained attention and as an environmental hazard rated third to air and water pollution (Khilman, 2004; Singh \& Daver, 2004). The harmful effects of noise on human health and development have been underestimated for a relatively long time. Apart from the discomfort and irritation, noise pollution can cause harm depending on its intensity, duration and frequency. Stansfeld and Crombie, (2011) and Kempen et al., (2006) reported that there is an association among environmental noise exposure and hypertension and ischemic heart disease. Exposure to acute noise influences the body`s compensatory mechanics to stress (Maschke et al., 2000; Babisch, 2002), causes increased blood pressure and vasoconstriction (Berglund et al., 2000), contributes to heart attack, learning disabilities and tinnitus (Moszynski,2011) and its effect on physiological functions in humans can be temporal or permanent (Lercher et al., 1993; Babisch et al., 2005a). As we grow older, our hearing often declines due to several factors. The loss of hearing results from occasional infections in the inner ear and from the natural aging of the sound receptors (Chiras, 2001). Persistent loud noise can cause premature degeneration of the sensory cells inside the ear leading to deafness. According to one estimate, one in every ten to twenty people suffers some hearing loss from anthropogenic noise (Chiras, 2001). The need for studies regarding urban noise pollution and its consequences on the environment has motivated various researches on the problem in several countries (Armah et al. 2010; Ugwuanyi et al., 2005; Zeid et al., 2000; Zheng et al., 1996). Although noise pollution is attracting attention of policy makers, not much consideration has been given to noise produced from educational institutions like the universities where some students resort to noise-making in their bid to reduce stress from academic pressure. The Ghana Environmental Protection Agency (GEPA) has intensified public education on noise pollution particularly in secondary and tertiary institutions. This educational campaign was motivated by the realization that most students were unaware of noise exposure and its associated health hazards as well as regulation governing noise pollution. The present study is essential as it is critical to the implementation of more practical noise assessment and monitoring activities on university campuses.

The following objectives were formulated to guide the study:

1. To measure the noise levels in selected halls of residence in the University of Cape Coast (UCC) and ascertain which halls are in compliance.

2. To carry out source apportionment for the noise generated in the halls of residence and determine the peak period of the noise generated.

3. To determine whether there is association between noise levels and irritation of students across the halls of residence.

\section{Materials and Methods}

\subsection{Study area}

The study was conducted in the halls of residence on UCC campus. The university has six (6) halls of residence (fig. 1) which accommodate mostly the first year students. There are two same - sex halls, Casely Hayford, populary called Casford (males) and Adehye (females) and four halls with both sexes namely; Valco, Nkrumah, Oguaa and Atlantic. The locations and populations of the halls are: Adehye ( $05^{\circ} 06^{\prime} 18.8^{\prime \prime} \mathrm{N} 001^{\circ} 17^{\prime} 10.8^{\prime \prime} \mathrm{W}$ ) 480 students, Casford ( $05^{\circ} 07^{\prime} 00.4^{\prime \prime} \mathrm{N} 001^{\circ} 17^{\prime} 03.8^{\prime \prime} \mathrm{W}$ ) 727 students and 113 National Service Personnel, Valco ( $\left.05^{\circ} 06^{\prime} 57.4^{\prime \prime} \mathrm{N} 001^{\circ} 16^{\prime} 57.0^{\prime \prime} \mathrm{W}\right) 1300$ students and Oguaa ( $\left.05^{\circ} 06^{\prime} 16.4^{\prime \prime} \mathrm{N} 001^{\circ} 17^{\prime} 9.4^{\prime \prime} \mathrm{W}\right) 950$ students.

\subsection{Data collection and Analysis}

A sound level meter (Philip harris sensor meter) together with structured questionnaire was used for data collection. The location of each hall was determined by means of a global positioning system [GPS] ( Etrex -Garmin ). 150 students were interviewed and based on the number of students in each hall, a specific number of the questionnaires were administered as follows: Adehye (21), Casford (32), Oguaa (39) and Valco (58). Questionnaires were checked whether they were properly completed and also for internal consistency at the close of each day. Besides demographic information, the questionnaire also included questions on possible non-auditory noise effects (noise annoyance from different sources, interference with various activities and sleep disturbance). A five point likert scale was used and internal reliability was assessed with the Cronbach alpha. Students were selected at random from the various floors of the hall with the view of getting information from every area of each hall and the questionnaires were completed by resident students. The results obtained were analysed using version 16 of Statistical Package for Social Sciences (SPSS). 
A $24 \mathrm{hr}$ noise measurement was conducted for a period of two months; from the month of February $\left(1^{\text {st }}\right)$ to the month of March $\left(26^{\text {th }}\right)$ for the four halls. The instrument was mounted at a standard height $160 \mathrm{~cm}$ at the various locations and the noise level measurements were taken. Measurements were made at the various Junior Conference Rooms (JCR), various floors of the halls, porters' lodges and hawking centres inside the halls where noise generated through conversations, arguments, music, shouting, banging of doors, dawn prayers and preaching, among others were recorded. A-weighted instantaneous sound pressure level $\left(\mathrm{L}_{\mathrm{Ai}}\right)$ measurements were recorded. For each location, two noise level measurements were taken on different days. During each day`s measurement three replicates were taken and the average noise level computed. All measurements were done in accordance with the time specifications of the Ghana EPA (Table 1). The first measurements were for the day readings and these were taken between the hours of 06.00-22.00. Morning readings were carried out at 07.00-13.00, afternoon readings were carried out at 13.00-19.00 hours and the evening readings were carried out between the hours of 19.00-22.00. The second readings were carried out for the night measurements which took place between 22.00-06.00 hours. Two measurements were taken; between the hours of 22.00-01.00 and 04.00-06.00. The noise measurements were carried out for eight weeks.

\section{Results}

\subsection{Noise levels in the various halls of residence}

The assesssment of noise levels in the halls of residence of the University of Cape Coast has shown that Oguaa and Valco were acoustically polluted. The average sound levels measured in these halls: Oguaa, $L_{d a y}=60$ decibels $(\mathrm{dB})$ and $L_{\text {night }}=55 \mathrm{~dB}$; Valco, $L_{\text {day }}$ and $L_{\text {night }}=66 \mathrm{~dB}$ and $60 \mathrm{~dB}$ respectively - were well above the limits set for an educational facility like a university by the Ghana Environmental Protection Agency. For Adehye and Casford, noise levels were within the permissible limits. Adehye recorded $49 \mathrm{~dB}$ and $45 \mathrm{~dB}$ as day and night readings respectively while Casford's measurements were $54 \mathrm{~dB}$ for the day and $48 \mathrm{~dB}$ for the night readings (fig 2). About $55.7 \%$ of the students considered most of the sound from the halls as noise and $44.3 \%$ disagreed.

\subsection{Sources of noise in the various halls of residence}

From the students responses (Table 2), the major sources of noise in the selected halls of residence were arguments, followed by music. Adehye, Casford and Valco had their main source of noise being generated through arguments. On the other hand, music was the main source of noise in Oguaa hall. However, results from the measurement of noise levels $(\mathrm{dB})$ from the various sources in the halls (Table 3) showed that 'morale' (students gathering to chant songs to entertain themselves) generated the most noise for Oguaa, Casford and Valco whereas dawn prayers and preaching was the source of highest level of noise for Adehye hall. Only 12 respondents indicated that dawn prayers and preaching was a major source of noise but surprisingly the measured noise levels for dawn prayers and preaching in all the halls exceeded the Ghana EPA recommended levels.

\subsection{Perceptions of students on noise levels in the halls of residence}

The students perceptions about noise were mixed and sometimes weird. The reason given by those who felt irritated by the noise $(66.67 \%)$ was that it disturbs their sleep and studies and for those who did not feel irritated by the noise it serves as a source of entertainment in the hall. Interestingly, some respondents indicated that noise reduces stress and tension from academic pressure. About $56 \%$ of respondents were mostly irritated by noise in the evening and $22 \%$ felt mostly irritated by the noise at night. Again, $14 \%$ were irritated by the noise in the afternoon and $8 \%$ in the morning. Majority of the respondents (72\%) were of the view that noise in the halls should not be completely stopped. Ten students $(6.67 \%)$ out of the 150 interviewed had reported high noise levels to the university authorities, 94 of them (62.67\%) did not find it expedient to report and 45 students had other reasons for this. Majority of the respondents (57.7\%) were aware that Ghana EPA is responsible for enforcing regulations on noise levels, however, none of them had ever complained to the Ghana EPA about excessive noise levels.

\subsection{Association between noise levels and student irritation across halls}

The Chi-square test analysis on the association between noise levels and students irritation across halls (Table 4), shows that the P-Value (0.180) is greater than the alpha value (0.05) [Table 5], therefore we fail to reject the null hypothesis and conclude that, there is no association between the halls of residence of the students and their level of irritation by noise in the halls. 


\section{Discussion}

\subsection{Levels and distribution of noise produced in the halls of residence}

Noise generated within the functional units ranged from $30 \mathrm{~dB}$ to $70 \mathrm{~dB}$, with Adehye recording the lowest for both day $(49 \mathrm{~dB})$ and night $(45 \mathrm{~dB})$. On the other hand, Valco recorded the highest noise level for both day and night and these were $66 \mathrm{~dB}$ and $60 \mathrm{~dB}$ respectively. Oguaa had the second highest recording of $60 \mathrm{~dB}$ for the day's readings and $55 \mathrm{~dB}$ for the night. Casford, the only male hall recorded $54 \mathrm{~dB}$ and $48 \mathrm{~dB}$ respectively for day and night readings. It is not surprising that the only female hall recorded the lowest noise level for both day and night for the entire study. Most of the students residing in the hall agreed that most of the sound generated within is not noise. Most of the noise was generated early in the mornings between the hours of 6.00-7.00 when the ladies were preparing to go for lectures and this short period of time was insignificant to increase the general noise level for the day.

Among the sources of noise in the various halls, 'morale' generated the highest level of noise of $94 \mathrm{~dB}$ and $90 \mathrm{~dB}$ in Casford and Valco halls respectively. This source of noise was however, not frequent. Valco had music to be the most frequent source of noise and Adehye had its main source of noise to be conversation (57dB). Valco hall recorded the highest noise levels during the study for both day and night. This could be attributed to the fact that it has the highest total number of students among the halls selected for this study. For this reason, a lot of different noise sources such as music, arguments, among others with different frequencies were generated within this hall. Moreover, it has a quadrangle where as the noise echoes; much of the noise is trapped within rather than escape. This supports the notion that architectural design and structure of buildings influence noise retention. Furthermore, most of the students in this hall agreed to the fact that much of the sound produced within the hall could be classified as noise.

A surprising result of this study relates to Casley Hayford hall (the only male hall) which produced noise levels within the Ghana EPA permissible limit. This hall used to be noted for excessive noise making and unruly behaviour of some of the residents over the past years. This situation prompted the university administration to place ban on demonstrations, rallies and assemblies and this may account for the acceptable level of noise generated. Although Oguaa hall is the largest hall on campus, it was not the hall that produced the loudest noise; nevertheless, its noise measurements were still above the permissible limits. This could be due to the fact that the structural design of this hall is not amenable to noise retention such that eventually most of the noise generated is dissipated. Much of the music, which was a major source of noise in this hall, was coming from nearby restaurant and shopping centres so the echoes were not that intense to cause a significant change in the level of noise in the hall. Noise levels measured from dawn prayers and preaching in all the halls exceeded the Ghana EPA limit but only 12 respondents (8\%) indicated this as a major source of noise. Most of the students belong to various religious groupings and this observation could probably be due how the students perceive prayers and preaching as a sacred activity and are not prepared to comment on it.

\subsection{Day and time with loudest noise}

All the halls recorded higher noise levels during the day than night. The day's readings were taken between the hours of 7.00-23.00 and this is the time that most of the students' activities are carried out. Some of such activities are: preparation to lectures, watching a football match (which most at times resulted in strong arguments), entertainment through playing and dancing to music, and banging of doors, among others. During the night where readings were taken between the hours of 23.00-6.00, most students were asleep and so less noise was generated. The noise produced in all the halls during this time were from the students' cadet call and dawn prayers and preaching of the gospel. Although these sources of noise recorded as high as $84 \mathrm{~dB}$ and $70 \mathrm{~dB}$ respectively, they were not frequent and occurred within a relatively shorter period of time. Moreover, the days that the noise levels were high were Fridays and Saturdays. This could be attributed to the fact that during these days, students attend less or no lectures and are mostly engaged in different activities leading to noise generation. About $66.67 \%$ of the residents felt irritated by the noise in the various halls. The reasons given by those who felt irritated by the noise included disturbance of sleep and studies. Reading, problem solving and memorization are among cognitive effects most strongly affected by noise (WHO, 1999). Also, the critical effects of noise in places used for both dwelling and studies include sleep disturbance, speech interference, disturbance of information extraction and annoyance (Lisa Goines and Louis Hagler, 2007; Hobson, 1989). For those who did not feel irritated by the noise, they indicated that the noise enlivens the hall as it serves as a source of entertainment; and reduces stress and tension from quizzes. This perception however, contradicts the findings of Chiras (2001) who established that noise can cause fatigue, restlessness and tension. Again, it should be noted that each population has sensitive subpopulation such as individuals impaired by concurrent diseases and other 
physiological limitations that are at higher risk to noise exposure (Zaidi, 1999) and the vunerability to noise may be due to increased risk based on behaviour (willingly or imposed) and the inability to move away from noxious sources (Brookhouser, 1996; Pediatric committee on environmental health.2003). Moreover, some residents said they have adapted to the noise levels in the halls but according to Niemann et al. (2006), prolonged exposure to acute noise may cause susceptible individuals in the population to develop permanent health effects, which can reveal themselves ten to fifteen years after the time of exposure in different functional systems. Noise is a quantifiable environmental exposure that can trigger individual reactions and symptoms (Saadu et al., 1998) and even at levels that are not harmful to hearing, noise is perceived subconsciously as a danger signal, even during sleep (Babisch,2005b).

\subsection{Efforts taken by residents to reduce the noise generated within the halls}

Although more than half of the students agreed on the fact that the noise irritates them, $72 \%$ were of the view that noise in the halls should not be stopped totally. This could probably be due to the fact that most sources of noise in the halls are the basis of entertainment for the residents. This partly explains why $62.67 \%$ of respondents were unconcerned about the noise produced and only $6.7 \%$ had reported to the university authorities. $57.7 \%$ of respondents were aware that the Ghana EPA is responsible for enforcing regulations on noise levels, however, none of the individuals who were aware of the EPA's regulatory functions had ever lodged a complaint with the EPA. Generally the control of environmental noise has not been effective due to lack of knowledge about its effect on humans and about dose-response relationships. According to Tsai et al., 2009, studies and strategies to improve noise control are urgently needed. This confirms the fact that lack of strategies to improve noise control is responsible for the unacceptable noise recorded in the various halls of residence. The provision of effective and meaningful information on noise in any community would ensure good public education, improved legislation and enforcement of regulations (Lisa Goines \& Louis Hagler, 2007; Tsai et al., 2009).

\section{Conclusion}

The study showed that some halls of residence on the University of Cape Coast campus produced noise levels above the permissible ambient noise levels for day and night set by the Ghana EPA. Generally, the same sex halls produced noise within the acceptable limits unlike the halls with both sexes. The major sources of noise were 'morale' (students gathering to chant songs to entertain themselves), music and arguments. Noise generated in the halls of residence ranged from $30 \mathrm{~dB}$ to $70 \mathrm{~dB}$. Valco and Oguaa halls were acoustically polluted since their noise levels exceeded the Ghana EPA upper limit by $1-11 \mathrm{~dB}$ (A). Thus, there is the need to control the level of noise by enforcing regulations and promoting knowledge and awareness on the effects of noise, which will possibly lead to long term commitment to the reduction of noise levels.

\section{Acknowledgement}

We wish to express our profound gratitude to Rahmat Duker Quagraine for assisting us in the fieldwork.

\section{References}

Armah, F.A., Odoi, J.O., Yawson, D.O., Yengoh, G.T., Afrifa, EK.A., \& Pappoe, A.N.M. (2010). Mapping of noise risk zones derived from religious activities and perceptions in residential neighbourhoods in the Cape Coast metropolis, Ghana. Journal of Environmental Hazards: Human and Policy Dimensions, 9(4), 358-368.

Babisch, W., Beule, B., Schust, M., Kersten, M., \& Ising, H. (2005a). Traffic noise and risk of myocardial infarction. Epidemiology, 16, 33-40. http://dx.doi.org/10.1097/01.ede.0000147104.84424.24

Babisch, W. (2005b). Environmental Health Perspect. Noise Health, 113, A14-15

Babisch ,W. (2002). The noise/stress concept, risk assessment and research needs. Noise Health, 4, 1-11.

Berglund, B., Lindvall, T., \& Schwela, D.H. (2000). Guidelines for Community Noise. Geneva: WHO.

Brookhouser, P. E. (1996). Sensorineural hearing loss in children. Ped Clin N Amer, 43, 1195-1216. http://dx.doi.org/10.1016/S0031-3955(05)70514-9

Chiras, D. (2001). Environmental Science - Creating a sustainable future. ( 6 th ed ), London: Jones \& Bartlett, pp. 457-459.

Committee on Environmental Health. (2003). Handbook of Pediatric Environmental Health. American Academy of Pediatrics, Washington DC.

Environmental Protection Agency (EPA) - Ambient Noise Level Guidelines on Residential Areas, 2008, Ghana.

Hobson, J. A. (1989). Sleep. Scientific American Society Library. W. H. Freman and Company. New York. 
Kempen, E. Van., Kamp, I.V., Fischer, P., Davies, H., \& Stellator, R. (2006). Noise exposure and Children`s Blood Pressure and Heart rate: the RANCH project. Noise Health Journal, 11(44), 161-168.

Khilman, T. (2004). 'Noise pollution in cities, Curitiba and Goteborg as examples' In: Proceedings of the Seminar - Environmental Aspects of Urbanization - Seminar in Honor of Dr. Mostafa Kamal Tolba, Gothenburg, Sweden.

Lercher, P., Hortnagl, J., \& Kofler, W.W. (1993). Work noise annoyance and blood pressure: Combined effects with stressful working conditions. International Archives Occupational Environmental Health, 65, 23-8. http://dx.doi.org/10.1007/BF00586054

Lisa Goines, R. N., \& Louis Hagler, M. D. (2007). Noise Pollution: A Modern Plaque. Southern Medical Journal, 100, 287-294. http://dx.doi.org/10.1097/SMJ.0b013e3180318be5

Maschke, C., Rupp, T., \& Hecht, K. (2000). The influence of stressors on biochemical reactions - a review of present scientific findings with noise. International Journal of Environmental Health, 203, 45-53.

Moszynski, P. (2011). WHO warns noise pollution is a growing hazard to health in Europe. [Online] Available: http:/www.Bmj2011;342:d2114.doi;10.1136/bmj.d2114 (April, 2011)

Niemann, H., Bonnefoy, X., Braubach, M., Hecht, K., Maschke, C., Rodrigues, C., \& Robbel, N. (2006). Noise induced annoyance and morbidity results from the Pan/European LARES study.Noise Health Journal, 8, 9-32.

Stansfeld, S., \& Crombie, R. (2011). Cardiovascular effects of environmental noise: research in United Kingdom. Noise Health Journal, 13(52), 229-33. http://dx.doi.org/10.4103/1463-1741.80159

Saadu, A. A., Onyeonwu, R. O., Ayorinde, E. O., \& Ogisi, F. O. (1998). Road traffic noise survey and analysis in some major urban centers in Nigeria. Noise Control Engineering Journal, 46(4), 146-158. http://dx.doi.org/10.3397/1.2828467

Singh, N., \& Davier, S. C. (2004). Noise pollution- Sources, effects and control. Journal of Human Ecology, 16(3), 181-187.

Tsai, Kang-Ting., Lin, Min-Der., \& Chen, Yen-Hua. (2009). Noise mapping in urban environments: A Taiwan study. Journal of Applied Acoustics, 70, 964. http://dx.doi.org/10.1016/j.apacoust.2008.11.001

Ugwuanyi, J. U., Ahemen, I., \& Agbendeh, A. A. (2005). Assessment of environmental noise pollution in Markurdi Metropolis, Nigeria. Zuma Journal of Pure and Applied Sciences, 6(2), 134-138.

WHO. (1999). Guidelines for Community Noise. Occupational and Environmental Health (OEH), Geneva

Zaidi, S. H. (1999). An epidemiological study of hearing impairment in the Himalayan territories of Pakistan. Hearing International Newsletter, 8, 1-4.

Zeid, Q., She, M., \& Abdel-Razia, I. R. (2000). Measurement of the noise pollution in the community of Araba. Acoustica, 86, 376-378.

Zheng, X. (1996). Study on personal noise exposure in China. Applied Acoustics, 48, 59-70. http://dx.doi.org/10.1016/0003-682X(95)00061-D

Table 1. Ambient Noise Level Guidelines of EPA, Ghana

\begin{tabular}{|c|c|c|c|}
\hline \multirow[t]{2}{*}{ ZONE } & \multirow{2}{*}{$\begin{array}{l}\text { DESCRIPTION OF AREA } \\
\text { OF NOISE RECEPTION }\end{array}$} & \multicolumn{2}{|c|}{$\begin{array}{c}\text { PERMISSIBLE NOISE } \\
\text { LEVEL } \\
\text { IN dB (A) } \\
\end{array}$} \\
\hline & & $\begin{array}{c}\text { DAY } \\
0600-2200\end{array}$ & $\begin{array}{c}\text { NIGHT } \\
2200-0600\end{array}$ \\
\hline A & Residential areas with negligible or infrequent transportation & 55 & 48 \\
\hline B1 & Educational (school) and health (hospital) facilities & 55 & 50 \\
\hline $\mathrm{B} 2$ & Area with some commercial or light industry & 60 & 55 \\
\hline $\mathrm{C} 1$ & $\begin{array}{l}\text { Area with some light industry, place of entertainment or public } \\
\text { assembly and place of worship such as churches and mosques }\end{array}$ & 65 & 60 \\
\hline $\mathrm{C} 2$ & Predominately commercial areas & 75 & 65 \\
\hline $\mathrm{D}$ & Light industrial areas & 70 & 60 \\
\hline $\mathrm{E}$ & Predominately heavy industrial areas & 70 & 70 \\
\hline Source: & Ghana EPA 2008 & & \\
\hline
\end{tabular}


Table 2. Sources of noise in the halls of residence and the students' response

\begin{tabular}{cccccc}
\hline & \multicolumn{5}{c}{ Halls of residence } \\
\cline { 2 - 6 } Sources of noise & Adehye & Oguaa & Casford & Valco & Total \\
\hline Music & 5 & 11 & 6 & 19 & 30 \\
Morale & 1 & 7 & 8 & 7 & 23 \\
Arguments & 6 & 6 & 14 & 8 & 45 \\
Dawn prayers and preaching & 4 & 2 & 1 & 5 & 12 \\
Cadet & 1 & 0 & 1 & 1 & 3 \\
Hawkers & 0 & 1 & 0 & 3 & 4 \\
Music and Argument & 0 & 1 & 2 & 4 & 7 \\
Morale and Music & 2 & 5 & 0 & 5 & 12 \\
Morale and Argument & 2 & 5 & 0 & 6 & 13 \\
\hline Total & 21 & 38 & 32 & 58 & 149 \\
\hline
\end{tabular}

Table 3. Measurements of noise levels $(\mathrm{dB})$ from various sources in the halls

\begin{tabular}{lcccc}
\hline & \multicolumn{3}{c}{ Halls of residence } \\
\cline { 2 - 5 } Sources of noise & Adehye & Oguaa & Casford & Valco \\
\hline Music & 53 & 72 & 62 & 84 \\
Morale & 0 & 85 & 94 & 90 \\
Arguments & 57 & 74 & 80 & 67 \\
Dawn prayers and preaching & 64 & 67 & 69 & 70 \\
Cadet & 0 & 0 & 84 & 83 \\
Hawkers & 50 & 40 & 30 & 45 \\
\hline
\end{tabular}

Table 4. A cross tabulation between the halls of residence and level of irritation

\begin{tabular}{lcccccc}
\hline & \multicolumn{5}{c}{ Level of irritation } \\
\cline { 2 - 7 } Hall of residence & Not at all & Slightly & Moderately & Very & Extremely & Total \\
\hline Casford & 1 & 3 & 8 & 4 & 1 & 17 \\
Adehye & 1 & 1 & 6 & 3 & 5 & 16 \\
Valco & 2 & 2 & 10 & 15 & 9 & 38 \\
Oguaa & 0 & 1 & 6 & 9 & 13 & 29 \\
\hline Total & 4 & 7 & 30 & 31 & 28 & 100 \\
\hline
\end{tabular}

Table 5. Chi-Square Tests

\begin{tabular}{cccc}
\hline & Value & Degree of freedom & Asymp. Sig. (2-sided) \\
\hline Pearson Chi-Square & $16.253^{\mathrm{a}}$ & 12 & 180 \\
Likelihood Ratio & 17.575 & 12 & 129 \\
\hline
\end{tabular}




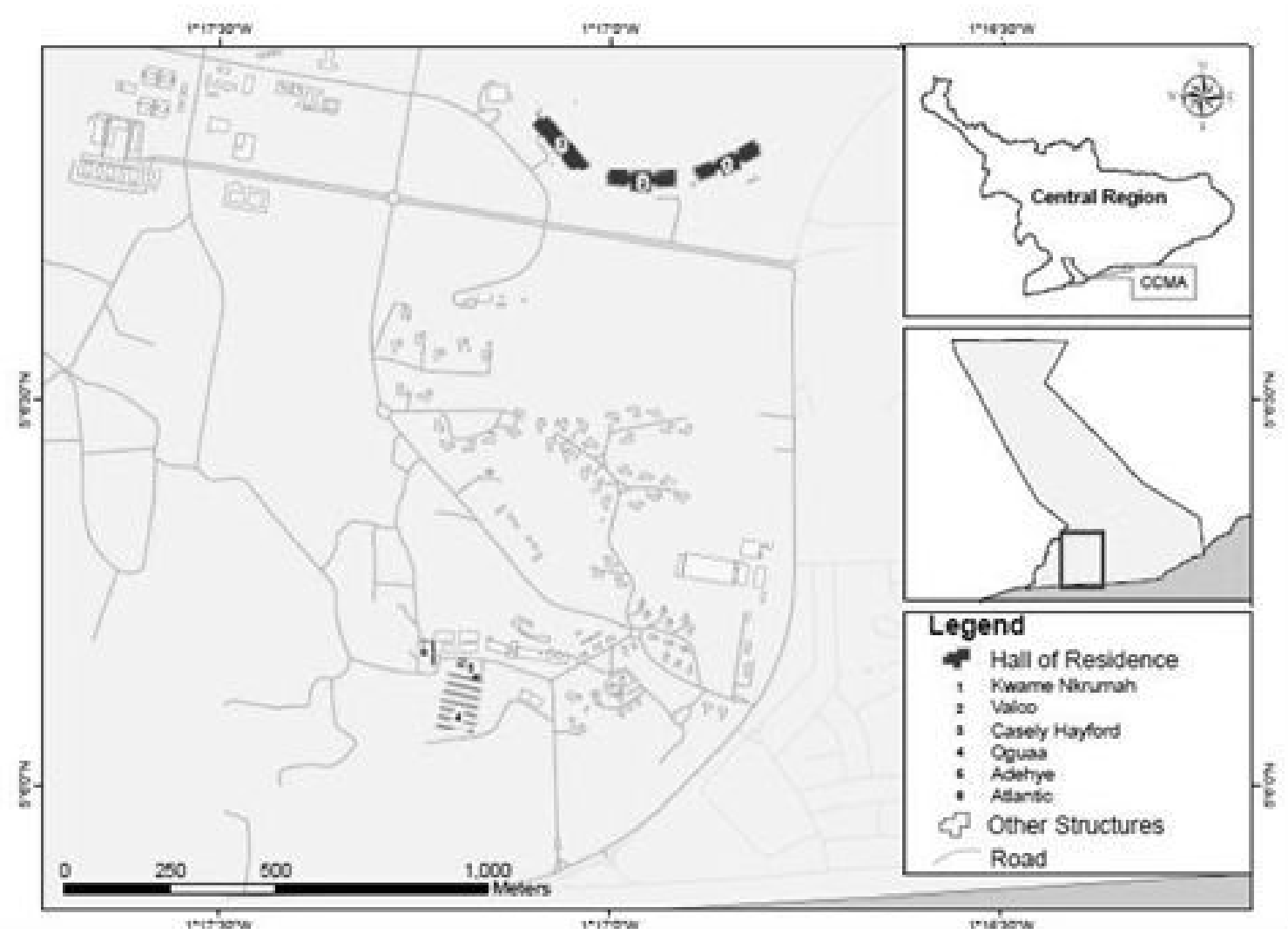

Figure 1. A map of the University of Cape Coast showing halls of residence



Figure 2. The noise levels $(\mathrm{dB})$ in the various halls of residence for both day and night readings 